\title{
HUMANOS, MÁS HUMANOS EN TIEMPOS DIFÍCILES
}

\author{
Humans, more Humane in Difficults Times
}

\author{
Analyda Boluarte Drago \\ Universidad Femenina Sagrado Corazón \\ Lima - Perú \\ https://orcid.org/0000-0003-3973-9227 \\ analydaboluarted@unife.edu.pe
}

\begin{abstract}
RESUMEN
Dentro de la actual emergencia sanitaria que vivimos a nivel mundial y a nivel nacional por el COVID 19, hemos sido testigos de diversas manifestaciones humanas que en otras circunstancias podrían pasar desapercibidas. Es realmente en las situaciones límite en donde salen a la luz las grandezas y las más bajas mezquindades. El presente artículo reflexiona en torno a la crisis en la que nos encontramos a raíz del COVID - 19. Valida, en el primer apartado, si la adversidad puede ser una oportunidad. En el segundo apartado, procuraremos iluminar al ser humano de modo que se pueda ponderar si tenemos las condiciones necesarias para autodeterminar nuestros pasos hacia una mejora personal, a pesar del entorno adverso. En el último apartado, se resalta el papel primordial que tiene la educación en la tarea de ganar en humanidad y en la excelencia personal.
\end{abstract}

\section{Palabras clave:}

Crisis, persona, perfección humana, virtud, resiliencia, esperanza.

\begin{abstract}
Within the current health emergency that we are experiencing globally and nationally due to COVID - 19, we have witnessed various human manifestations, which in other circumstances would go unnoticed. It is really in extreme situations where the greatness and the lowest of pettiness come to light. This article reflects on the crisis in which we find ourselves as a result of COVID -19. It validates, in the first section, whether adversity can be an opportunity. In the second section, it tries to enlighten the human being so that it can be considered whether we have the necessary conditions to self-determine our way towards personal improvement despite the harsh environment. The last section highlights the primary role that education has in the task of gaining humanity and personal excellence.
\end{abstract}

\section{Keywords:}

Crisis, person, human perfection, virtue, resilience, hope. 


\section{Amenazas y oportunidades en un contexto de crisis}

Es innegable que nos encontramos en un contexto de emergencia sanitaria, que está impactando en distintos ámbitos de la vida y de modo muy diverso. Esta situación es ya, motivo de una conmoción existencial que suscita en nosotros muchos interrogantes.

Haciendo un poco de memoria, recordaremos que el término "virus" hacía referencia a los diversos virus digitales que podían afectar el espacio web o disco duro, con el poder implacable de destruir nuestros datos. Hoy sabemos que, las afecciones virales trabajan mano a mano en ambas dimensiones, la real y la virtual. (Žižek, 2020)

La palabra crisis, proviene del vocablo griego krisis (decisión) y krino (separar); así pues, conlleva ruptura, pero al mismo tiempo esperanza y oportunidad. Si bien la crisis conduce a cambios importantes en la vida, también permite tomar decisiones y reformular la propia jerarquía de valores. Uno de los efectos más contundentes de las crisis graves, es que nos ayudan a recalibrar las prioridades vitales.

La pandemia nos ha enfrentado violentamente con una verdad: nos ha mostrado con nueva luz nuestra vulnerabilidad, la imposibilidad de protegernos perfectamente mediante la predicción y el control. Muchos hemos pasado por situaciones dolorosas, pérdidas de familiares, empleo, estabilidad económica y sanitaria. En muchos casos, ni siquiera se ha podido acompañar a nuestros seres queridos en su enfermedad, despedirse de ellos y vivir el duelo.

De pronto nos encontramos imposibilitados de realizar las cosas más habituales y el ámbito espacial también se limitó. Por otro lado, el distanciamiento social es algo que nos va afectando a todos de manera distinta. Dentro de este contexto, las emociones negativas como el estrés, la fatiga, y el pánico pueden ser tan contagiosas como el coronavirus y sus nuevas cepas. Todo aquello que parecía sólido e incontestable ha sido cuestionado y vulnerado.

Un panorama así, podría resultar sombrío o bastante desalentador. ¿Cabría decir que es la mirada con la que interpretamos lo que sucede a nuestro alrededor? Quisiera traer a nuestra reflexión, las circunstancias por la que pasaron dos personas, que supieron resignificar o darle un sentido a la situación de crisis que les tocó vivir.

En primer lugar, podríamos mencionar a Karol Wojtyla, filósofo polaco. Al día de hoy Santo. Nace en 1920. Sus primeras experiencias con el sufrimiento empezaron desde su niñez. Su mamá muere cuando tenía 8 años. Su hermano médico -al que Karol admiraba mucho- muere a raíz de una epidemia al contagiarse de la escarlatina. En 1941 muere su padre cuando él tenía 21 años. Se queda solo.

Según refiere Weigel, Polonia en esos momentos se encontraba entre Alemania y la entonces Unión Soviética, antes de la segunda guerra mundial. En 1939 se da la invasión a Polonia por parte de la Alemania Nazi. En ese tiempo, Karol como joven de la época estudiaba filología polaca, le gustaba la literatura, teatro, drama. No puede seguir estudiando y empieza a trabajar en una cantera para poder sobrevivir.

Ve cómo sus amigos más cercanos van muriendo por la guerra. Tenía amigos judíos. Los profesores de su universidad, 
van desapareciendo o fallecen; porque era una prioridad atacar la cultura polaca.

¿Cómo veía él esta situación? Wojtyla tiene una visión muy particular del sufrimiento. Desde la mirada de un joven, que trepaba montañas, esquiaba, nadaba, hacía canotaje, estudiaba y trabajaba; sufre, pero busca la manera de darle un sentido, de resignificar las circunstancias, el mismo sufrimiento. (Weigel, 1999)

Podemos preguntarnos ¿Por qué esas difíciles circunstancias personales que eran una amenaza no le hundieron, sino que curtieron su personalidad? ¿Cuál fue su actitud ante los obstáculos que encontró en su vida? Si leemos su biografía, nos damos cuenta, que el sufrimiento fue para él una oportunidad de crecer y desarrollarse; fue una oportunidad de prepararse para ser quién fue.

Otro personaje que puede iluminar nuestras reflexiones es Viktor Frankl. Psiquiatra, neurólogo, psicólogo y filósofo del siglo XX. Nace en Austria, es de origen judío y fue prisionero en cuatro campos de concentración. Tuvo la oportunidad de "resignificar el dolor y el sufrimiento".

Hablar del sufrimiento en Frankl, es hablar del sentido de la vida. Frankl observó algunas circunstancias que hacían que los prisioneros sobrevivieran. Era porque tenían un sentido por qué vivir. Algunos tenían una obra literaria que terminar, encontrar a su familia, un hallazgo científico; pero el sentido de la vida era lo que alineaba la fortaleza que se necesitaba en el cuerpo, en el alma y en el corazón para sobrevivir en tiempos de guerra.

Si bien Frankl tuvo como maestros a Sigmund Freud y Alfred Adler; la esencia de su teoría psicológica fue desde una experiencia vital. Vive la experiencia límite y luego se decepciona de los presupuestos que asumió como discípulo de aquellos dos grandes psicoterapeutas.

Desde la mirada de Frankl, el ser humano ahora se nos presenta como el hombre en busca de sentido, por lo que detectará sobre todo limitaciones en aquellas dos visiones del ser humano. Es así, que sus argumentos en torno al sentido de la vida "se desplaza en forma de interrogante y cuestionamiento al reduccionismo hallado en el psicoanálisis y en el adlerianismo" (Chávez, 2009, pp. 36-37).

Frankl planteaba, que tiene que haber un motor que mueva al hombre, más allá de lo que sus instintos le determinaban hacer. Ese motor es el "sentido". Descubrió que los que lograron sobrevivir ya sea para trascender o para hallar una manera digna de vivir el sufrimiento o la muerte, fueron los que tenían "un por qué vivir". En última instancia, desde su pensamiento, "los valores que permiten trascender al yo no son los valores de utilidad ni de dominio" (Chávez, 2009, p. 41).

Integrar la dicotomía entre el sufrimiento y la esperanza no es fácil; ambas caras de la moneda existen y coexisten. Aunque seamos conscientes que el sufrimiento es parte de la vida humana, para nadie es agradable. Dice Frankl: "justamente allí se le puede dar sentido a la vida, pues entonces podemos realizar lo más humano dentro del hombre y eso lo constituye su facultad de transformar aun una tragedia -a nivel humano-en un triunfo" (1991, p. 229).

Es verdad que como ellos puede haber muchos, pero lo significativo que propongo en este paralelo de vidas, es la coincidencia ante las situaciones 
adversas, que los lleva a resignificar el sufrimiento y valorar más a la persona en su integridad.

Metafóricamente podríamos decir que en la actualidad estamos en "tiempos de guerra", aludiendo a la crisis sanitaria, económica e incluso psicológica por la que estamos atravesando y el impacto que deja en nuestras vidas. Lo cierto es que, cuando se emprende la búsqueda del sentido del dolor, el ser humano se cuestiona sobre el sentido de su misma existencia y trata de aclarar el alcance y el significado de su propia libertad. En esta misma línea, podrían surgir otras preguntas como: "¿Puedo rechazar el dolor? ¿Puedo, acaso, fijar una distancia del dolor, eliminarlo? El dolor le imprime a la vida su sentido efímero" (Lewis, 1990, p. 40).

Como afirma Frankl, la capacidad para sufrir forma parte de la propia educación, es una fase importante del crecimiento interior y también de la autorganización. Lo cierto es que no estamos preparados para afrontar el dolor, el sufrimiento físico y espiritual que está ocasionando el coronavirus. Por el contrario, nos mantiene atrapados en tres coordenadas de emergencia: la médica (la propia epidemia), económica -que está golpeando duramente-, y la del impacto en la salud mental (Žižek, 2020).

Pero son justamente estas circunstancias que estamos viviendo, las que nos permiten salir de nosotros mismos. Son una oportunidad para reflexionar acerca de: ¿qué es lo esencial en la vida? ¿qué es lo que da sentido a nuestra vida? Frankl nos animaría a enfrentarnos a la adversidad y sacar nuestra mejor versión; nos diría: "precisamente allí donde la situación es irreversible, allí se nos exige que cambiemos, es decir que maduremos, que crezcamos, que nos trascendamos. Y eso es posible hasta el momento de la muerte" (Frankl, 1991, pp. 230-231).

Frente a las dificultades podemos adoptar diversas actitudes. Una de ellas es pensar -con cierta resignación y pesadumbre - que es una pena, que encima de lo propio del día a día, haya dificultades.

Por el contrario, podemos también mirar las dificultades -sin negar la resistencia que oponen- como el camino ordinario a través del cual damos densidad, peso y sentido a las metas que emprendemos. De esta manera, el obstáculo se convierte en oportunidad para poner en juego la grandeza de ánimo que nos hace crecer y madurar.

Es innegable, que las circunstancias que estamos viviendo, nos interpelan a gestionar la propia angustia, la propia incertidumbre, pero: ¿Nos volveremos por ello más humanos? ¿Aprovecharemos la puerta abierta por el COVID -19 como una oportunidad de renovarnos, de ser mejores personas?

Hay modos de pensar que no son los más adecuados para acertar en la toma de decisiones y de lo que se trata es cambiar, también los hábitos de pensar. Es así, que una misma situación puede generar humanidad o erosionar lo más humano.

En cualquier caso, el palpar nuestra fragilidad puede convertirse en un resorte que abra del todo la ventana de humanidad, dándonos cuenta que podemos perfeccionarnos; a pesar de las dificultades.

Dejemos que las reflexiones nos ayuden a validar si son circunstancias que suponen una amenaza; o quizá desde otra 
mirada, las podamos considerar como una oportunidad.

\section{El reto de la excelencia personal}

En una crisis como la que estamos viviendo, no nos tiene que llamar la atención que se presente un desequilibrio y pasado un tiempo se logre una resolución, que puede manifestarse de dos maneras: en nuestra capacidad de avanzar o de retroceder ante la situación límite que se experimenta. Es verdad que la crisis se puede resolver bien o mal, puede terminar en crecimiento o en pérdida y aunque suponga riesgo; hay que afrontarla.

Somos conscientes, que como seres humanos podemos realizar hazañas virtuosas o ser protagonistas de las más viles acciones. Somos frágiles, vulnerables y cometemos errores. Pero también está dentro de nuestras posibilidades renacer como el Ave Fénix mitológico; rehacernos y afrontar con valentía cualquier infortunio. Frankl nos recuerda que: "El hombre es ese ser que ha inventado las cámaras de gas; pero es también ese ser que caminó en dirección a esas cámaras de gas en actitud erguida o rezando el Padre nuestro o con la oración judía de los agonizantes en los labios" (Frankl, 1987, p.268).

No nos tiene que extrañar, que en estos tiempos de crisis a raíz de la pandemia del COVID-19 nos paralicemos, haya desconcierto e incluso podríamos perder la brújula. Por eso como dijimos en párrafos anteriores, hace falta detenernos, tomar distancia y hacernos preguntas esenciales: ¿Quién soy? ¿Con qué cuento? ¿Qué puedo hacer? De estas reflexiones, sacaremos impulso para mejorar como personas y mejorar a quienes están a nuestro alrededor. Las respuestas nos permitirán reafirmar o reconducir nuestros pasos hacia un mejor rumbo.
Tenemos todo un potencial para poner en acción y alcanzar nuestros fines. Contamos con unas facultades que nos ubican en una situación distinta a cualquier ser vivo. Aristóteles nos diría que hagamos uso de nuestra razón, al afirmar que "sólo el hombre, entre los animales, tiene logos" (Prevosti, 2011, p.7).

No cabe entonces poner tope a nuestra humanidad, o ser ya demasiado humanos, tal como se titula una obra de Nietzsche. Por el contrario, Ser cada vez más humanos nos lleva a la excelencia personal. En este sentido, también los tiempos difíciles son propicios para reformular nuestro proyecto de vida, descubrir lo mejor de lo que somos capaces, así sea costoso; pero que vale la pena alcanzarlo.

Ser humano no significa ir más allá de lo humano, sino intensificar lo humano, profundizar en lo más humano; teniendo en cuenta que el horizonte más importante no se encuentra allá lejos, sino más adentro.

Traigo a nuestras reflexiones al filósofo francés Paul Ricoeur, quien llamó "maestros de la sospecha" a Freud, Marx y Nietzsche. Ellos sospechaban de la razón, como omnipotente, autofundante, autosostenible, protagonista del progreso y bienestar. Consideraban que incluso al autoexaminarse, sería difícil que la misma razón sea autotransparente y la autocrítica.

En concreto Nietzsche, autor que inspira el título y propuesta quizá antagónica del presente artículo, consideraba que era necesario estar en un permanente estado de sospecha respecto a la razón, la tradición y todo lo pasado. Esta postura le llevará a cuestionar las identificaciones entre el bien, la belleza, 
la justicia y la religión. Denunciando esto y más "como las grandes ilusiones de occidente" (Huitrón, 2018).

Centrándonos en perspectiva de Nietzsche, el hombre no es un individuo sino parte de un continuo existencial. Es un producto de fuerzas distintas de él, que no llega a controlar. Él mismo se resiste y lamenta ante esta realidad, considerando que tan solo puede cambiar el contexto, pero sigue siendo humano. En el texto mencionado en párrafos anteriores Nietzsche afirma que "la humanidad no tiene en su conjunto ningún fin, y, por consiguiente, el hombre, examinando su marcha total, no puede encontrar en ello consuelo ni reposo, sino, por el contrario, desesperación" (Nietzsche, 1986, pp. 49-50).

Una primera interrogante que vamos a intentar despejar es: ¿en qué aspectos el ser humano puede crecer como persona? Un personalista como Polo diría: "Lo más característico del ser humano es que puede ir a mejor y también a peor. Se puede ir hacia un mundo más humano y también hacia un mundo menos humano" (2012).

En este sentido, nos viene bien traer a nuestras reflexiones, las facultades con las que contamos, como son la inteligencia y la voluntad. Con la inteligencia, nos ponemos en disposición de llegar a la verdad, adecuamos el pensamiento a lo que las cosas son, comparamos, distinguimos, establecemos relaciones, profundizamos en los problemas, intentamos solucionarlos. Nos conviene entonces, hacer uso de dos grandes capacidades de la inteligencia: la capacidad reflexiva y la capacidad proyectiva.

Será un aporte interesante, si a lo cognitivo le añadimos lo conativo. Quien nos introduce en este concepto será Spinoza, para quien tan solo los seres humanos pueden llegar a ser conscientes de su conatus (deseo), y esta conciencia es una de las condiciones para analizar los propios afectos.

Es así como, en la medida que una persona se comprende mejor a sí mismo y al entorno, comenzará a vivir en un mundo más amplio y complejo que antes desconocía; expandiéndose el campo de su conciencia. Desde la perspectiva Spinozista, es "el conatus, lo que caracteriza a un sujeto, no es que la mente o los juicios racionales lleguen a controlar el cuerpo, sino que son las afecciones de las que es capaz" (Bula, 2012, p. 49).

Asimismo, la posibilidad de crecimiento sugiere libertad. La persona humana es fundamentalmente libre para perfeccionar perfeccionándose; es libre para crecer y, por lo tanto, existe también la libertad de renunciar a nuestro crecimiento personal.

Si la libertad es enarbolada desde la mirada de Nietzsche se suscitaría un lamento y desaliento ante visión pesimista de la naturaleza humana puesto que "La vida humana está profundamente sumergida en la contraverdad; el individuo no puede sacarla de ese pozo sin horrorizarse de su pasado, sin encontrar sus motivos presentes, desprovistos de toda razón de ser" (Nietzsche, 1986, p. 50).

Es importante resaltar que la plenitud llama al crecimiento personal y éste se consigue integrando las tendencias y dimensiones que componen la naturaleza humana. Aspirar a ser mejor es, pues, el único crecimiento irrestricto del ser humano que nos mantiene vivos y con ilusión. Por lo tanto, "no hay ninguna 
persona que esté como previamente señalada para fracasar en la vida, mientras que otras tuvieran en su frente la señal de las seleccionadas para el triunfo" (Llano, 2002, p. 23).

Somos conscientes que saber a dónde queremos ir, no basta. La inteligencia ya hizo lo suyo y es ahora cuando empieza el trabajo de la voluntad. Toca ponerles dinamismo a estos propósitos. Con la voluntad queremos y hacemos lo que nos hemos propuesto; pero esto supone un entrenamiento; no es espontáneo.

El esfuerzo se orienta a conseguir que en ella arraiguen hábitos firmes, disposiciones permanentes para obrar Desde siempre a estos buenos hábitos de la voluntad se les ha llamado virtudes, cuyo aprendizaje es diferente al de los saberes operativos de la inteligencia. Para adquirir una virtud, no basta saber que existe, es necesario tenerla como propia para que nos dispongan a la acción efectiva. Se aprende practicándolas y se enseña por contagio desde la ejemplaridad.

Los hábitos constituyen la clave del crecimiento de lo más humano del ser humano. Hábito es una disposición operativa, una pauta de pensar o de actuar que nos predispone y facilita ir, con el pensamiento y la conducta, en la dirección que hemos decidido darles. Cuando son buenos -cuando nos disponen a pensar bien y a actuar bien- los hábitos reciben el nombre de virtudes; en el caso contrario se denominan vicios.

En la tradición Aristotélica es la práctica de la virtud, la búsqueda de la excelencia, la que permite la realización humana. Para Aristóteles la virtud -aretér, es una excelencia añadida a algo como perfección. De este modo, "A lo que hoy denominamos "virtudes", lo llamaban los griegos "excelencias" y los latinos "fuerzas" (Llano, 2002, p.36).

Aristóteles distingue dos tipos de virtudes: las intelectuales o dianoéticas, y las morales o éticas. Las primeras perfeccionan al sujeto en diversas facetas del uso de la razón discursiva (en griego, diánoia), y las segundas le capacitan para obrar bien en el plano moral.

En Ética a Nicómaco, Aristóteles consideraba la virtud como una cierta sabiduría práctica afirmando: "Debe decirse, pues, que toda virtud (areté) perfecciona el buen conducirse de aquel ser del que es virtud, y hace estimable su operación" (ÉN II06a, 14ss). Asimismo, plantea un elenco detallado de las virtudes, pero todas pivotan sobre cuatro que considera fundamentales, y que la tradición posterior ha denominado cardinales porque constituyen el quicio (cardo, cardinis) o eje sobre el que se sitúan las demás. Estas son: la prudencia, justicia, templanza y fortaleza.

El Estagirita considera que la virtud es un término medio entre dos extremos precisando que "La virtud es, por tanto, un hábito selectivo, consistente en una posición intermedia para nosotros, determinada por la razón y tal como la determinaría el hombre prudente" (ÉN II06b 15-20).

Aristóteles se refería a los hábitos con la expresión segundas naturalezas. A diferencia de la naturaleza primaria o esencial -el modo de ser con el que nacimos-, la segunda naturaleza es el modo de ser que nos "hacemos ser" obrando, pensando y actuando de manera habitual.

El aporte tomista al tema de la virtud puede resumirse en la clásica definición 
"hábito operativo bueno de la voluntad" (S.Th. I-II, qq. 49-67). La virtud es una cualidad operativa, es decir, una perfección de la voluntad que la refuerza para querer mejor. Es lo "último de la potencia" (S.Th., I-II, q.55, a.1, ad.1) porque la actualiza. Es decir, la virtud sería una perfección sobrevenida a la voluntad.

En este sentido, se podría decir que el ser humano: nace y se hace. La naturaleza biológica nos dota de una serie de propiedades que hacen posible que uno se vaya apropiando operativamente de otras -segundas naturalezas-, que son las que configurarán finalmente nuestro carácter; esa huella personal que cada uno imprime a su propia existencia. Desde la mirada de Nietzsche se procedería a la deconstrucción de la tradición aristotélica tomista afirmando que "no hay pecados en sentido metafísico, pero que tampoco hay virtudes en el mismo sentido; que todo este dominio de las ideas morales está continuamente en eterno vaivén; que hay conceptos más altos o más bajos del bien y del mal, de lo moral y de lo inmoral" (Nietzsche, 1986, pp. 72-73).

Nos va quedando claro, que las virtudes se adquieren gradualmente, con esfuerzo, pero dan soporte a una vida de calidad que quiere llegar a ser plena. El tema de fondo es la excelencia personal; aquella calidad superior que nos lleva a mejorar no solo en el hacer, sino en el propio ser. Este proceso gradual implica, por un lado, ser conscientes de nuestra propia condición humana y de estar hechos para crecer.

En este sentido, se abre ante cada persona un abanico de posibilidades de excelencia personal, incluso en situaciones adversas. Podríamos preguntarnos, si aún en estas circunstancias cabe el uso de la libertad con miras a esa excelencia. La respuesta desde una mirada personalista, sería que sí. Podríamos decir que, desde una crítica directa a la ética kantiana, Nietzsche también "reflexiona sobre el desarrollo de las virtudes humanas, y dice de ellas que deben ser personales y no impuestas desde el deber hacia un imperativo categórico" (Huitrón, 2018, p. 26).

Con la finalidad de precisar, pero sin ánimo de limitar, quisiera incidir en dos virtudes que son muy necesarias en las circunstancias que estamos viviendo: la esperanza y la resiliencia.

En palabras de Aristóteles, "la esperanza es el sueño del hombre despierto". Es que los sueños necesitan de la acción, del empuje, de la creatividad y de la resiliencia. En este sentido, la esperanza se presenta como una tarea que requiere un despliegue de la capacidad donal de la persona. En consecuencia, la entera estructura de la esperanza se obtiene no del análisis de la noción, sino de su integración en el hombre, es decir, atendiendo a las dimensiones humanas que concurren en el existir según la esperanza.

Podemos decir entonces que, la estructura completa de la esperanza humana consta de personas, tarea, recursos, riesgo (o adversarios), beneficiario y quien encarga la tarea (de quien procede la mayor ayuda). La existencia íntegramente vivida en esperanza implica todos estos elementos.

Desde luego, la esperanza implica sujeto: sin él la tarea es imposible y la esperanza sería utopía. Como la esperanza está en el orden del amor, exige un beneficiario o destinatario, el cual debe ser otro que el sujeto. Pero se precisa, además, que la tarea esté bien dirigida, es decir que, en definitiva, haya respuesta. 
Alguien me la ha encomendado: la tarea no es mía tan sólo desde mí, puesto que como persona estoy en relación con otros.

Quien quiere influir en el presente, tiene que tener una actitud positiva hacia el mundo en que vive. No debe mirar al pasado, con nostalgia y resignación, sino que ha de adoptar una actitud positiva ante el momento histórico concreto. Debería entonces, estar a la altura de los nuevos acontecimientos que marcan sus alegrías, preocupaciones, sus ilusiones y decepciones y todo su estilo de vida.

Pero lo importante es que, cuando esperamos algo, estamos motivados para poner los medios y conseguirlo. La esperanza impulsa a la acción y trae consigo el cambio que deseamos. La esperanza nos permite vivir en el presente con novedad hacia el futuro. No es idealismo, sino elegir responder a lo que nos depara la vida, a sacar un significado y ver un propósito en todo lo que se vive, especialmente en estos tiempos difíciles.

Pasamos entonces a hablar acerca de la resiliencia, que se define como la capacidad que una persona tiene para resistir y superar los avatares negativos de la vida. La resiliencia es la entereza más allá de la resistencia, que supone una buena tolerancia a las frustraciones, a los golpes de la vida

Los primeros estudios sobre la resiliencia, que datan del año 1972, se centraron en personas que habían vivido situaciones límites: campos de concentración, niños pobres que habitaban en las calles o mujeres maltratadas. No hablamos de resiliencia como una capacidad estática, sino como "procesos resilientes" que abarcan múltiples factores que se pueden entrenar, y que se puede enseñar. Se trata de fomentar lo que se llama resiliencia proactiva

Para Boris Cyrulnik, el padre de la resiliencia, significa: "la capacidad del ser humano para reponerse de un trauma $y$, sin quedar marcado de por vida, ser feliz". De una manera más precisa: es iniciar un nuevo desarrollo después de un trauma o una situación límite. Implica recuperarse frente a la adversidad para seguir proyectando el futuro.

Ser resiliente no significa que no sientas emociones negativas, sino que has aprendido a manejar mejor dichas emociones. Es una habilidad transversal que afecta a muchas áreas de la personalidad y que nos permite sobreponernos a los contratiempos. Permite también, desarrollar conductas positivas ante el estrés, las amenazas o algún conflicto.

Según Cyrulnik, las personas resilientes poseen tres características principales: saben aceptar la realidad tal y como es; tienen una profunda creencia en que la vida tiene sentido; y tienen una inquebrantable capacidad para mejorar.

Es importante aceptar el cambio que esa crisis demanda como una parte natural de la vida. Lo óptimo, es vivir el aquí y ahora de manera más tranquila; disfrutar lo que se tiene, sin preocuparse de si se perderá o no.

Algunos sinónimos que se pueden emplear para indicar la palabra resiliencia son fortaleza y resistencia. Si damos una mirada desde la tradición aristotélica tomista, podemos mencionar la virtud de la fortaleza, reconocida como una de las virtudes cardinales. En cualquier caso, "Es necesario entender cómo somos para 
llegar a ser lo que debemos o podemos ser. Es todo un ideal de excelencia humana, puesto lo que podemos llegar a ser no lo tenemos asegurado, es un fin, una tarea y una conquista" (Yepes, 1993).

Luego del desarrollo de la virtud de la esperanza y la resiliencia, nos toca poner los medios para desarrollarlas, interiorizarlas, hacerlas nuestras; de modo que nos ayuden a sobrellevar el impacto de la pandemia del COVID- 19 en nosotros. Siempre se debe buscar el cambio para mejorar: el cambio siempre es bueno, aun cuando en este momento no lo parezca. Teniendo la seguridad, que "la virtud garantiza la coherencia del tiempo biográfico, la unidad en el tiempo, en la historia del ser humano" (Castillo, 1996, p.10).

Quisiera resaltar, que, aunque en las reflexiones se ha puesto énfasis en las virtudes, hace falta incorporar otros dos elementos como son los bienes y las normas. De acuerdo a las concepciones éticas y al modo como se entienda la conexión entre ser y deber ser, podemos encontrar una mayor incidencia en alguno de estos elementos. En palabras de Nietzsche, la "verdadera moral", es la que corresponde a los señores, los hombres fuertes, que no buscan, en ningún momento, el elemento pasivo basado en la costumbre, ni tampoco la utilidad como medio de conservación de la comunidad" (Huitrón, 2018, p. 18).

Sin ánimo de desarrollar cada uno ellos, considero que hace falta apostar por una ética integral en la que se articulen tanto las virtudes, bienes y las normas. Aunque no se dará de modo inexorable ni riguroso, si podría darse una manifestación de excelencia, en una persona que practica unas virtudes, aprecia unos bienes y respeta unas normas. Puesto que "Las virtudes nos remiten a los bienes, éstos a las normas, que su vez nos llevan a las virtudes, y a la inversa" (Llano, 2002, p. 126).

Desde una ética integral, no cabe prescindir de ninguno de estos elementos que intervienen en la acción humana. Este planteamiento supone que cada persona, a través de las normas que iluminan su conciencia, tome decisiones en orden a su propia excelencia, humanizando los ambientes a los que pertenece

La historia de la humanidad nos permite ver el uso de la libertad, las decisiones de quienes nos precedieron en el tiempo. En unos veinte años o más los que hoy somos protagonistas, seremos parte de los libros de historia. Ojalá luego de esta crisis sanitaria, hayamos aprendido a ser mejores seres humanos, mejores personas.

\section{Educación y excelencia personal}

Si bien, el principio temporal y antropológico de una vida lograda es el entorno familiar en la que cada uno nace, el entorno siguiente a tener en cuenta es el de la educación formal, que permite el despliegue de todas nuestras facultades y la adquisición de habilidades.

Es oportuno precisar la etimología de la palabra educación. Como sabemos, viene de educare, que en latín significa extraer o sacar fuera; y educere, del latín moderno, que significa acompañar. En otras palabras, a los seres humanos no nos sale espontáneamente comportarnos como lo que somos, sino que necesitamos de los demás sean los padres o los educadores.

Educar supone proactividad e intencionalidad para acompañar a los 
educandos en su tarea de hacerse; supone orientar el ser y el hacer, en función a una concepción antropológica. No cabe en esta labor un simple dejar ser, puesto que "el hombre es fundamentalmente un ser optimable. "Tendrá todas las quiebras que se quiera y que no se niegan. Pero es menester verlo desde el punto de vista de su capacidad de perfección" (Polo, 1993, pp. 99-100).

Habría que apuntar desde la educación a una formación integral, que no solo transmita la ciencia y la técnica, sino que cultive humanidad. En este sentido, podríamos afirmar que: "Las competencias y destrezas instrumentales son aprendizajes significativos para un ser humano, pero si no crece como persona -y eso está más en el orden de los fines que en el de los instrumentos o mediosse quedan en meros sucedáneos" (Barrio, 2016)

La formación humanística tiene un lugar privilegiado en esta visión de la educación, puesto que supone un valor agregado. En este sentido "se hace mayor la exigencia de unidad entre objetivos de instrucción, que atiendan a los conocimientos, y los llamados objetivos de formación que atienden a la voluntad" (Castillo, 1996, p. 3). Este enfoque, nos llevaría sin duda, a plantearnos nuevamente los planes de estudio y los programas curriculares.

Si damos una mirada a la educación superior, por años las universidades se han focalizado en educar profesionales en diferentes áreas del conocimiento y en la preparación técnica de los alumnos de pregrado. Pero sería oportuno plantearnos las siguientes preguntas: ¿̇Qué tipo de desarrollo personal necesita un profesional hoy en día para convertir las necesidades en oportunidades y las vulnerabilidades en fortalezas? ¿Qué puede aportar una persona que no puede aportar un robot? ¿Qué cualidades hay que reforzar en la preparación profesional de modo que el egresado esté en condiciones de servir a la sociedad? ¿Será útil la formación humanística o aparentemente inútil?

Estas preguntas demandan unas respuestas que se alinean en la forja de la excelencia personal. Por lo que no llegan a ser suficientes los cursos de especialidad, no basta con los conocimientos teóricos y prácticos para formar futuros profesionales. Un verdadero valor agregado otorgará la formación humanística que reciban los alumnos desde la formación de pregrado. En este sentido, "la unidad en los planes de estudio, en los objetivos, y en las metodologías reclama una concepción unitaria del ser humano" (Castillo, 1996, p. 3).

Mientras que la técnica y las ciencias van avanzando, se hace más imperiosa la necesidad de recurrir al tesoro guardado milenariamente que proviene de los filósofos clásicos. En concreto, necesitamos volver a las Humanidades, para encontrar en ellas algunas claves que nos permitan formar a los futuros profesionales de modo que impacten positivamente en la mejora de la sociedad.

La pertinencia de la educación superior debe evaluarse desde lo que la sociedad espera, de modo que existe un vínculo entre los estudiantes, egresados con la empresa, centro laboral o futuros empleadores. No cabe duda que la formación académica integral debe incluir la formación técnica especializada propia de la carrera profesional, sin perder de vista que estamos formando personas y la formación en valores es importante. Porque lo "que antes se estimaba sin 
más como humano, lo éticamente positivo, lo solidario y humanista, pasa a ser considerado por muchos, desde Nietzsche, como "humano, demasiado humano" (Llano, 2002, p. 113).

Si nos remitimos al pensamiento clásico podemos considerar, en primer lugar, lo que afirma Aristóteles. El Estagirita percibe prácticamente una identidad entre estos tres elementos: vivir bien, actuar bien y ser feliz. Vivir bien y vivir felizmente, este es el fin de la más fuerte tendencia del hombre. En palabras de Garcés, la solución no está tan solo en una buena técnica educativa, porque de serlo hace mucho que tendríamos que haber dado con ella, aunque subsistiesen aún algunas dificultades de aplicación. Nos encontramos delante de algo más complejo, que reclama establecer una práctica a través de la cual los principios y valores puedan convertirse en acciones concretas. Únicamente las acciones harán vigentes los principios.

Va quedando claro, que no es suficiente centrarnos en las habilidades cognitivas, técnicas e incluso emocionales. Son muy importantes las habilidades y competencias propias de la disciplina o ciencia, pero siempre con la posibilidad de desarrollar competencias éticas. De esta manera estaremos brindando a los futuros profesionales, los recursos necesarios para discernir entre lo correcto y lo incorrecto; entre lo bueno y lo malo; asumiendo los desafíos y requerimientos del mercado laboral.

La propuesta educativa óptima - sin duda- sería la que apueste como prioridad, por la formación integral de la persona. Una formación transversal que integre la ciencia, la tecnología y al mismo tiempo genere un espacio humanístico en el ámbito académico.

\section{CONCLUSIONES}

A modo de conclusión, quisiera resaltar que si bien la pandemia del COVID -19 ha mostrado de modo patente nuestra vulnerabilidad; también ha puesto en evidencia, que somos capaces de grandes acciones, capaces de revertir o sobrellevar una situación adversa.

Destacamos la virtud de la esperanza y la resiliencia, como anclas donde nos podemos asir para afrontar las dificultades. De modo que, si las circunstancias son adversas, siempre se puede elegir la actitud con la vamos a afrontarlas; viéndolas como una oportunidad de crecer, de perfeccionarnos.

Es una realidad que los seres humanos somos perfectibles $y$, aunque tengamos fallos y caídas, siempre está la posibilidad de crecer como personas en distintas dimensiones, ser más humanos, ser mejores.

Esta mejora es una tarea que se va forjando con las virtudes que cada quien considera necesaria para alcanzar una vida lograda. Es algo que depende del carácter de las personas, que brota de nuestra naturaleza fruto del esfuerzo y acaba por consolidarse, según el decir de Aristóteles, en una especie de segunda naturaleza. Gracias a esta segunda naturaleza se pueden equilibrar, bajo el consejo de la prudencia, el reconocimiento de nuestra vulnerabilidad y dependencia con la legítima aspiración a la autonomía personal.

Se ha precisado, que lo óptimo es una ética que integre las virtudes, principios y bienes. El apelar tan solo al deber o a la norma, resulta insuficiente puesto que aisladamente no perfecciona a la persona. Mientras que la ética de las virtudes, 
tiene la sutileza de mirar al fondo de la naturaleza humana, encontrando allí lo necesario para que se generen actos virtuosos y por efecto boomerang regrese a la misma persona, perfeccionándola aún más.

No podríamos dejar de mencionar el rol tan importante que tiene la educación en la excelencia personal. Se requiere una educación que aspire a ayudarnos a ser más humanos, integrando la ciencia, la tecnología y las humanidades dentro de su propuesta.

Con la globalización, se hace más patente que somos ciudadanos del mundo y ciudadanos de un país, formamos parte de una comunidad, llevamos las huellas de una cultura, de unas tradiciones; por lo que resulta de vital importancia que la educación se oriente a enseñar cómo asumir el reto de entrelazar lo particular y lo universal.

Esto supone una revisión de mallas curriculares y una válida discusión desde el ámbito académico; que podemos considerar como una tarea pendiente.

\section{REFERENCIAS BIBLIOGRÁFICAS}

Aristóteles (1985) Ética Nicomómaco. [traducción y notas de Julio Pallí Bonet]. Gredos

Barrio, J. M. (1989). La educación moral y el Proyecto de Reforma de las enseñanzas no universitarias. Revista Española de Pedagogía, No 184: 507-518. https://revistadepedagogia.org/ wp-content/uploads/2018/03/6La-Educaci\%C3\%B3n-Moraly-el-Proyecto-de-Reforma-delas-Ense\%C3\%B 1 anzas-noUniversitarias.pdf
Barrio , J.M. (2007) Dimensiones del crecimiento humano. Volumen 10, $\mathrm{n}^{\circ}$ 1, pp 17-134. Universidad de la Sabana. https:// educacionyeducadores.unisabana. edu.co/index.php/eye/article/ view/681/765

Barrio, J. M. ( 2016). Homo Adulescens : elementos para una teoría antropológica de la educación. Universidad Austral Teseopres. https://ia800902.us.archive.org/4/ items/BarrioMaestreHomoAdules cens/udec/Barrio\%20Maestre\%20 -\%20Homo\%20Adulescens $\% 20$ -\%20judec.pdf

Bula Caraballo, G. (2012) . Spinoza: empoderamiento y ética de la composición. Universitas PhilosoPhica 58, año 29: 197-215 enero-junio. http://www.scielo.org.co/pdf/unph/ v29n58/v29n58a09.pdf

Camps, V. (2016). Diccionario Iberoamericano de Filosofía de la Educación. Universidad Autónoma de Barcelona. https:// fondodeculturaeconomica.com/ dife/definicion .aspx? $\mathrm{l}=\mathrm{VE}$ id $=30$

Camps, V. (1990). Virtudes públicas. Espasa-Calpe

Castillo, G. (1996). La unidad de la vida humana. (Aristóteles y Leonardo Polo). Anuario Filosófico, 29 (2), 415-426. Universidad de Piura. https://pirhua.udep.edu. pe/bitstream/handle/1 1042/1582/ La unidad de la vida humana (Aristoteles_y_Leonardo Polo). pdf?sequence $=1$

Castillo, G. (2001). ¿Cómo comprender al hombre de 
hoy? En L. González (Ed.), Reflexiones sobre los ismo: III Coloquio de Filosofía, (pp. 2540). Universidad de Piura_https:// pirhua.udep.edu.pe/bitstream/ handle/11042/1651/Como. comprender al hombre de hoy. pdf?sequence $=1$ EisAllowed $=y$

Cyrulnik, Boris. (2002) Los patitos feos. La resiliencia una infancia infeliz no determina la vida. Editorial Gedisa.

Chávez, I. (2009) Alfred Adler y Viktor Frnakl: El discurso acerca del sentido de la vida. Avances Psicología 17(1) Enero - Diciembre. http:// www.unife.edu.pe/publicaciones/ revistas/psicologia/2009/ ivanmchavez.pdf

David, F. (1993). Strategic Management. Macmillan Publishing Company.

Di Giorgi Fonseca, L. (2013). Los afectos, las ideas y la formación de sujeto en Spinoza. Universidad del Rosario, 2013. https://www.google. $\mathrm{com} / \mathrm{search} ? \mathrm{q}=\mathrm{luz}+$ helena $+\mathrm{di}+$ giorgi + fonseca + spinoza\&oq $=$ luz +helena + di+giorgi+fonseca + spinozaEaqs $=$ chrome..69i57 $\mathrm{j} 33$ i10i160.15334j0j15Esourceid= chromeEie $=$ UTF $-8 \#$

Fazio, Mariano. (2009). Secularización y Cristianismo. Las corrientes culturales contemporáneas. Universidad Libros.

Frankl, Vicktor. (1987). El hombre doliente. Fundamentos antropológicos de la psicoterapia. Editorial Herder

Frankl, Viktor. (1991). La voluntad de sentido. Editorial Herder.
Frankl, Viktor. (1994). Ante el vacío existencial. Editorial Herder.

García González, Juan A. (2019). El hombre como persona. Antropología filosófica. Ideas y Libros.

Garcés Giraldo, Luis Fernando. (2015). La virtud aristotélica como camino de excelencia humana y las acciones para alcanzarla. Discusiones Filosóficas. Año $16 \mathrm{~N}^{\circ}$ 27, julio. pp. 127 - 146. http:// www.scielo.org.co/pdf/difil/v16n27/ v16n27a08.pdf

Grimaldi, E. ( 2004) . La ética de los bienes en Charles Taylor. Cuadernos de Filosofía. Excerpta e dissertationibus in Philosophia, 14 (2004) pp. 9-75. Servicio de Publicaciones de la Universidad de Navarra. https://dadun.unav. edu/bitstream/10171/6663/1/ GRIMALDI\%2C\%20EDGARDO.pdf

Huitrón, A. (2018). La forja de una identidad ética en el pensamiento de Nietzsche. En-claves del pensamiento, vol. XII, núm. 23, 00001 . https://www.redalyc.org/ jatsRepo/1411/141156420001/ html/index.html

Kant, E. (1998) .Crítica de la razón práctica. Sígueme.

Kant, E. (2005). Metafísica de las costumbres. Tecnos.

Jaeger, W. (1988). Los ideales de la cultura griega. Fondo de Cultura de México. https:// detemasytemas.files.wordpress. com/2012/05/32726025-wernerjaeger-paideia-los-ideales-de-lacultura-griega-iii.pdf 
Lapel, Viviana (2017). La noción de virtud en Leonardo Polo. Repositorio institucional PIRHUA. Universidad de Piura. https://www.leonardopolo. net/docs/Noci\%C3\%B3n\%20 virtud\%20Polo.pdf

Lewis, C.S. (2006). El problema del dolor. Editorial Rialp.

Lewis, C.S. (2018). Diario de un dolor. Adelphi.

Llano, Alejandro. (2002). La vida lograda. Editorial Ariel.

MacIntyre, A. (1987). Tras la virtud. Paidós.

MacIntyre, A. (2001). Animales racionales $y$ dependientes. Paidós.

Nietzsche, F. (1986). Humano, demasiado humano. Trad. de: Jaime Gonzales: Editores Mexicanos Unidos. https:// saudeglobaldotorg1.files. wordpress.com/2013/08/te1 nietzsche-humano.pdf

Pieper, J. (1997). Las virtudes fundamentales. Rialp.

Polo, L. (1985). Seminario de Antropología. Programa de Alta Dirección (PAD), Universidad de Piura.. https:// www.leonardopolo.net/docs/ SeminarioAntropologiaPAD.pdf

Polo, L. (1993) Presente y futuro del hombre. Rialp.

Polo, L. (1996). Ética: Hacia una versión moderna de los temas clásicos. AEDOS.
Polo, L. (1998) ¿Quién es el hombre? Un espíritu en el tiempo. Rialp.

Polo, L. (2005) Nietzsche como pensador de dualidades. Eunsa

Polo, L. (2007). Persona y libertad. Eunsa.

Polo, L. (2011) La esencia del hombre. Eunsa.

Polo, L. (2012). Filosofía y economía. Eunsa

Ponti, Franc. ¿Qué es eso llamado crecimiento personal? Seis vías para aproximarse a esa utopía. Capital Humano. $\mathrm{N}^{\circ} 184$, pp. 72-83. Enero 2005. https://www.navarra. es/NR/rdonlyres/41921452-74F84AF4-8E9E-72994D446082/15845 5/5crecimientopersonal.pdf

Prevosti, A. (2011). La naturaleza humana en Aristóteles. Espíritu: cuadernos del Instituto Filosófico de Balmesiana, ISSN 0014-0716, Año 60, $N^{\circ} .141$. https://www. revistaespiritu.org/la-naturalezahumana-aristoteles/

Rojas, E. (2000). La ilusión de vivir. Instrucciones para navegar hacia la felicidad. Vivir mejor.

Tomás de Aquino. (1994) Suma de Teología (tomo I), Parte I. BAC.

Tomás de Aquino. (1989). Suma de Teología (tomo II), Parte I-II. BAC.

Vargas, Alberto. (2011). La oportunidad moderna: del miedo a la esperanza. La crisis de la modernidad según Leonardo Polo. 
Revista de prepublicaciones del Instituto de Estudios Filosóficos Leonardo Poloserie de Filosofía, n 31. http://www. leonardopolo.net/docs/MP31.pdf

Weigel, George. (1999). Biografía de Juan Pablo II. Testigo de la Esperanza. Plaza y Janés.

Yepes Stork, R. (1993). Entender el mundo de hoy. Editorial Rialp.

Yepes Stork, R. y Aranguren, J. (1997) La persona y su intimidad. Cuadernos de Anuario Filosófico. Serie Universitaria, n० 48. https://dadun.unav.edu/ bitstream/10171/6360/1/48.pdf
Zchmann, E. (1957). El pensamiento de S. Freud y su aporte a la psicología. Revista Colombiana de Psicología, ISSN-e 0121-5469, Vol. 2, N. 1, 1957, págs. 68-74. https://dialnet.unirioja.es/servlet/ articulo?codigo $=4895303$

Žižek, Slavoj. (2020). Pandemic!: Covid-19 Shakes the World. CEOPS (Centro De Estudios De Orientación Psicoanalítica). https://dialektika. org/2020/04/11/pandemic-covid19-shakes-the-world-slavoj-zizek/

Fecha de recepción: 14/10/2021 Fecha de aceptación: 29/10/2021 